\title{
QUEEN'S
UNIVERSITY
BELFAST
}

\section{Demand Side Management of an Urban Water Supply Using Wholesale Electricity Price}

Kernan, R., Liu, X., McLoone, S., \& Fox, B. (2017). Demand Side Management of an Urban Water Supply Using Wholesale Electricity Price. Applied Energy, 189, 395-402. https://doi.org/10.1016/j.apenergy.2016.12.082

\author{
Published in: \\ Applied Energy
}

Document Version:

Peer reviewed version

Queen's University Belfast - Research Portal:

Link to publication record in Queen's University Belfast Research Portal

Publisher rights

(c) 2016 Elsevier Ltd. This manuscript version is made available under the CC-BY-NC-ND 4.0 license http://creativecommons.org/licenses/by$\mathrm{nc}-\mathrm{nd} / 4.0 /$,which permits distribution and reproduction for non-commercial purposes, provided the author and source are cited.

\section{General rights}

Copyright for the publications made accessible via the Queen's University Belfast Research Portal is retained by the author(s) and / or other copyright owners and it is a condition of accessing these publications that users recognise and abide by the legal requirements associated with these rights.

Take down policy

The Research Portal is Queen's institutional repository that provides access to Queen's research output. Every effort has been made to ensure that content in the Research Portal does not infringe any person's rights, or applicable UK laws. If you discover content in the Research Portal that you believe breaches copyright or violates any law, please contact openaccess@qub.ac.uk. 


\title{
Demand Side Management of an Urban Water Supply Using Wholesale Electricity Price
}

\author{
R. Kernan*, X. Liu, S. McLoone, B. Fox \\ School of Electronics, Electrical Engineering and Computer Science, Queen's University Belfast
}

\begin{abstract}
Municipal water supply consumes large quantities of electrical energy to move water from catchment areas to service reservoirs near centres of population. Pumping does not necessarily occur round the clock, but rather when necessary to uphold constraints relating to reservoir levels and system pressure. There is a degree of flexibility in the timing of pumping that makes it an excellent candidate for Demand Side Management, meaning that it can provide opportunities for improving power system operation and reducing electricity costs for the water utility. The extent of this flexibility depends on a number of factors. This study examines the optimisation of two water supply systems - the 'Van Zyl' benchmark system and a representation of the supply for the city of Belfast, Northern Ireland. The potential to employ intelligent operation of pumps to help bolster uptake of variable wind generation is assessed, as is quantification of the potential savings for a water utility. The results show significant potential savings for the water utility as well as a substantial increase in the utilisation of wind power.
\end{abstract}

Keywords: Demand Side Management, Real Time Pricing, Genetic Algorithms, Wind Energy, Renewable Energy, Optimisation, Water Pumping

\section{Nomenclature}

$i \quad$ Time period $(\mathrm{i}=1,2, \ldots 24,60 \mathrm{~min} /$ period $)$

$m \quad$ Mourne supply

n Lough Neagh supply

$d \quad$ Inside pipe diameter (m)

$h_{f} \quad$ Head loss (m)

$C \quad$ Hazen-Williams pipe roughness coefficient

$L \quad$ Pipe length (m)

$Q \quad$ Volumetric flow rate $\left(\mathrm{m}^{3} / \mathrm{s}\right)$

$E_{i} \quad$ Electricity cost, $i^{\text {th }}$ period (£)

$W_{i} \quad$ Wind generation as $\%$ of total in $i^{\text {th }}$ period

$F_{p, i} \quad$ Pump $p$ flow rate, $i^{\text {th }}$ period (1/s)

$M_{i} \quad$ Energy cost per unit, $i^{\text {th }}$ period $(\mathfrak{f} / \mathrm{kWh})$

$D_{p, i} \quad$ Flow from service reservoir $p, i^{\text {th }}$ period (1/s) $\quad 16$

$P_{p, i} \quad$ Pump $p$ energy consumption, $i^{\text {th }}$ period $(\mathrm{kWh}) 17$

$R_{p, i} \quad$ Service reservoir $p$ water volume, $i^{\text {th }}$ period (1) 18

$R_{p, \max } \quad$ Maximum water volume, service reservoir $p(1){ }^{\prime 9}$

$R_{p, \min } \quad$ Minimum water volume, service reservoir $p(1)_{20}$

${ }^{*}$ Corresponding author

Email address: rkernan01@qub.ac.uk (R. Kernan)

\section{Introduction}

The drive to phase out fossil-fired generation has increased investment in renewable generation. In Northwest Europe, wind is an abundant renewable resource [1], and, as such, significant efforts have been made to increase the penetration of wind generation in power systems.

Ireland, although composed of two political jurisdictions (the Republic of Ireland and Northern Ireland), has one synchronised power system and Single Electricity Market (SEM). The Irish power system supports a relatively small population of 6.5 million people and has $750 \mathrm{MW}$ of HVDC interconnection with Britain [2]. A target of $40 \%$ of all electricity is to come from renewable sources by 2020 , predominantly from wind power [3]. This target causes some issues for the Irish system, some of which are unique due to its relative isolation and limited available interconnection.

Modern wind turbines, unlike traditional synchronous generators, do not provide inertia to the power system as their rotating masses are connected to the grid through power electronics. Significant power system inertia mitigates frequency transients during system faults 
and large disturbances [4], and hence it is necessary to 74 maintain a minimum level of system inertia. Unlike 75 other countries with high penetrations of wind power (such as Denmark), Ireland has only limited HVDC interconnection, which provides no inertial support. Because of this constraint, System Non-Synchronous Penetration (SNSP) is currently limited to $55 \%$ on the Irish power system [5], with any renewable generation above this level wasted. Due to its variable nature, wind power is non-dispatchable apart from curtailment by a system operator.

In order to meet the high targets for wind power integration, it is estimated that the SNSP limit would have to be raised to $70 \%$ to avoid excessive curtailment [2]. This will be a significant challenge, especially for conventional generators [5], but presupposes that generation must be varied to meet a varying demand beyond the operator's influence. Under this regime, the system operator would have more problems when controlling a power system with high penetrations of wind power than one without. Dispatchable generation would see much greater variation in output in order to address wind variability, which is undesirable as it prevents generators operating at their most efficient settings.

Demand Side Management (DSM) provides a means of mitigating the regulation duty of conventional generation. DSM has traditionally been seen as a method whereby a system operator or utility would exert direct ${ }_{101}$ control over load [6]. The main contribution of this ${ }_{102}$ work is in investigating whether market-driven DSM ${ }_{103}$ can provide improvements in wind power utilisation to 104 the power system without explicit system operator inter- 105 vention, but rather by the load responding to changes in 106 system price. This is the first study to optimise a water ${ }_{107}$ network on the basis of Real-Time Pricing (RTP) and ${ }_{108}$ quantify both the energy cost savings and wind power 109 utilisation.

\section{Scope for Optimising Water Supply}

\subsection{Demand Side Management}

With DSM, supply of managed load is encouraged ${ }_{116}$ when net demand (consumer demand less renewable ${ }_{117}$ generation) is low. The incentive is the lower cost of ${ }_{118}$ electricity at such times. Conversely, the supply of man- 119 aged load is discouraged when net demand, and elec- 120 tricity price, are high. The boost to net demand when ${ }_{121}$ renewable generation is plentiful eases the SNSP constraint.

DSM is regarded as an important part of the future ${ }_{124}$ operation of power networks and as such has been the ${ }_{125}$ focus of a number of studies. Where DSM has been carried out based on energy cost, it has primarily been on the basis of Time of Use (ToU) pricing [8][9][11]. These are multi-rate tariffs which change several times a day. Although promoting energy use during off-peak times, ToU tariffs do not track the actual market price of electricity and thus do not provide an incentive for consumers to respond to specific events, such as generator outages or high-wind scenarios. ToU tariffs reflect only the general trends of electricity cost and usually have no more than four changes per day. Increased penetrations of variable generation such as wind generation mean that price peaks do not always occur at the same time of day, as high penetrations of low marginal cost generation during peak times reduce the need for low merit generation, thus reducing market prices. ToU tariffs do not reflect these day-to-day variations. An RTP tariff, based on the wholesale cost of electricity, offers a realistic means of tracking the variation in system price.

RTP-based DSM has been implemented in [12]-[15] with significant savings in energy cost. Finn et al. in [14] optimised residential load on the basis of RTP and saw increases in wind power utilisation of up to $23.3 \%$, while in [15], RTP-based optimisation of industrial loads saw wind power utilisation increase by $5.8 \%$ while also reducing energy cost.

A common theme is the aggregation of flexible residential loads through the use of smart meters and a central controller in order to minimise decision making and maximise savings [7]-[9]. Such schemes have the disadvantage of involving a large number of stakeholders (residential consumers) who must voluntarily submit to having their energy consumption controlled externally. However, the potential has been shown for significant savings in energy costs for consumers. Vanthournout et al. in [10] found that it was difficult to maintain involvement of residential consumers in RTP schemes due to response fatigue - automation was required in order to make it viable.

DSM has also been demonstrated as being viable for provision of balancing reserve for wind generation [9].

Industrial loads frequently have a higher degree of operational flexibility than residential loads [13],[15]. Industrial consumers represent $42 \%$ of global electrical consumption. Industrial units are large compared to residential or commercial loads and are centrally controlled and owned, reducing the complexity of co-ordination and thus making them very attractive for DSM [16]. In [13], DSM of aggregated residential load was compared with that of representative commercial demand and a number of typical industrial processes. A 


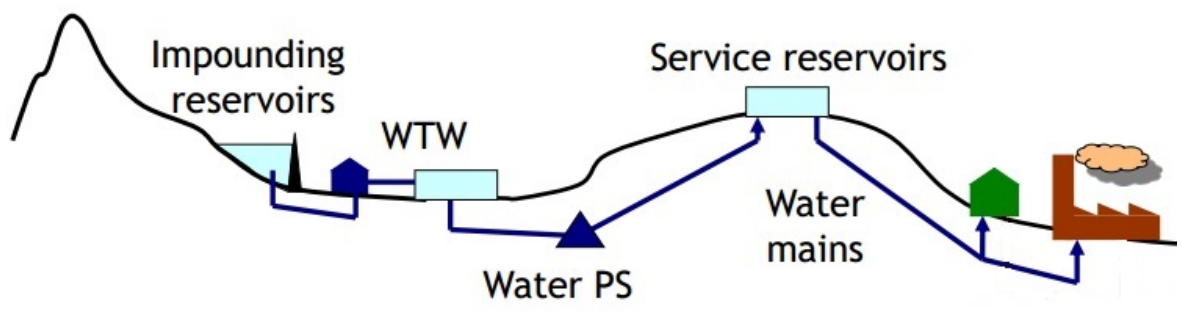

Figure 1: Layout of a water supply network

$10 \%$ saving in energy costs was seen with the industrial 164 DSM, compared to $5.8 \%$ for commercial and 5\% for 165 residential. Similarly high savings were also seen in 166 [12].

\subsection{Public Water Supply}

Public water supply is an excellent candidate for the application of DSM due its significant potential for a large number of operating modes. Water networks are centrally owned and controlled and would require minimal modification to allow optimised operation.

Water pumping can be classed broadly as an interruptible load. In [16], a steel mill was optimised on the basis of several smart pricing scenarios. Under each pricing model, optimal scheduling resulted in higher profit, although higher profits were seen with ToU pricing compared to RTP - the steel mill which was modelled operated on a batch cycle, meaning that once a batch started it could not be interrupted ${ }_{167}$ - making it less suitable for taking advantage of the 168 higher level of variability of RTP compared to ToU 169 pricing. Water pumping can be interrupted, provided 170 reservoir level constraints are maintained and wear 171 from pump switching is considered. The basic layout 172 of a water supply system can be seen in Fig. 1. Large, 173 centrally controlled pumps are used to move water 174 from catchment areas to service reservoirs (SRs) near 175 centres of population, from which water flows to 176 consumers. The hydrostatic head of these SRs is used 177 to maintain system pressure and, as long as SR water 178 levels are maintained between minimum and maximum 179 levels, there is a high degree of flexibility over the 180 timing of pumping. The electricity demand of Northern 181 Ireland Water (NIW) accounts for approximately 3\% 182 of all electrical demand in Northern Ireland, a figure 183 representative of water supply systems worldwide. $\quad 184$

NIW oversees $26,700 \mathrm{~km}$ of water mains, supplying 185 563 million litres of water per day to 1.8 million people. 186
A total of 23 impounding reservoirs supply more than 370 supply reservoirs [17].

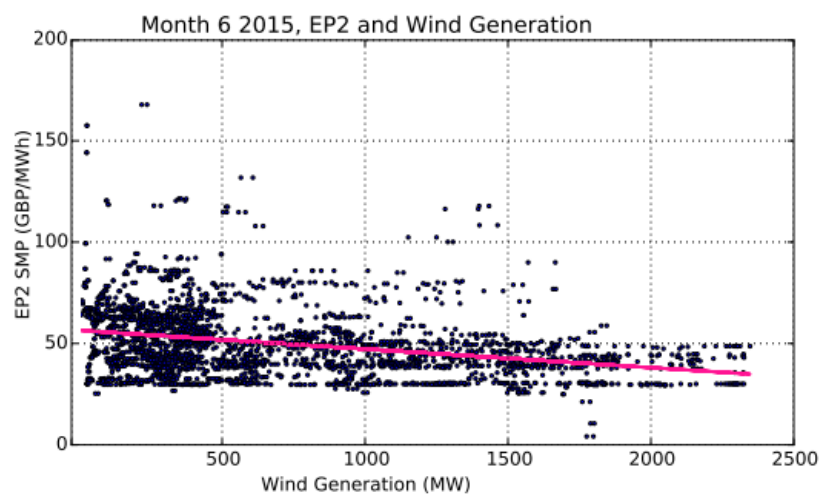

Figure 2: SMP and wind generation, June 2015

Many of NIW's facilities are run on ToU tariffs. NIW have carried out basic optimisation at some of their pumping stations in the past, trying to carry out as much pumping as possible during low-price periods.

In the SEM, System Marginal Price (SMP) changes every 30 minutes and reflects the operating cost of the single most expensive generator required to fulfill demand [20]. The higher the penetration of wind generation on the power system, the lower the requirement for expensive generation. Since wind is considered to have no marginal cost, higher wind penetrations should result in a lower system cost. Fig. 2 shows the final SMP plotted against wind generation for one month in 2015. It is clear from this graph that there is some degree of correlation between wind and SMP: this can be explained by the current conservative operation of the power system. When wind penetrations are high, marginal generation is not decommitted but rather dispatched down. This policy, though resulting in generators running at low efficiencies, gives the system operator a margin for 
error with regard to wind forecasting uncertainty. At 235 very high wind penetrations such a policy would not be justifiable.

SMP-based optimisation of load would nonetheless ${ }^{237}$ help to flatten the demand curve, as it would promote ${ }^{238}$ operation during low demand and low price scenarios ${ }^{239}$ while discouraging consumption during peak periods.

There are several different 'versions' of SMP. The ac- ${ }^{241}$ tual price paid to generators (termed as Ex Post 2 or ${ }^{242}$ EP2) is not published by the SEM Operator (SEM-O) ${ }^{243}$ until four days after the day in question (D+4). A full ${ }^{244}$ day forecast (Ex-ante 1, EA1) is made available at 11:00 ${ }^{245}$ one day before actual trading. This is updated at 16:00 ${ }^{246}$ with the Ex-Ante 2 or EA2 forecast, and again at 9:30 ${ }^{247}$ on the day itself with the Within Day 1 (WD1) forecast ${ }^{248}$ [21]. It is on the basis of these forecasts that pump- ${ }^{249}$ ing optimisation is proposed in this work. Optimising 250 demand on the basis of the forecast wholesale price of 251 electricity could provide a means to increase the uptake ${ }^{252}$ of wind generation by encouraging demand when wind ${ }^{253}$ generation is high as well as minimising the price paid 254 by the consumer.

In [14], Finn et al. carried out a 6-month study on 256 a domestic dishwasher, optimising operation based on ${ }^{257}$ EA1 and EP2 SMP. EP2 optimisation saw energy cost 258 decrease by more than $20 \%$ and wind power utilisa- ${ }^{259}$ tion increase by $23.5 \%$, while EA1 optimisation saw ${ }^{260}$ a $17.5 \%$ reduction in cost and wind power utilisation increase by $16.9 \%$. The inherent uncertainty of price forecasting means that it would be almost impossible to make the savings seen in the EP2 scenario. This study 262 found that scheduling load on the basis of the EA1 fore- ${ }^{263}$ cast was a viable way to reduce energy costs and im- 264 prove wind power utilisation.

In [22], Paudyal et al. applied an industrial load man- 266 agement model to a simplified representation of a water 267 pumping facility, based on one day of data relating to 268 an RTP tariff in Ontario, Canada. A 38.1\% decrease 269 in energy costs compared to non-optimised operation 270 was observed. This simulation, although short in du- 271 ration and disregarding hydraulic constraints, is notable 272 in that it considers the impact of water pumping optimi- 273 sation on the power system, citing its implementation as 274 a means by which system operators could reduce peak demand.

DSM of water networks is cost effective and tech- 276 nically feasible, and price based optimisation of water 277 networks has been carried out in the past [22]-[30].

\section{Optimisation}

Various methods have been proposed for pumping optimisation, including linear programming [23], non-linear programming [24] and dynamic programming [25]. Heuristic methods, particularly Genetic Algorithms (GAs), have been used successfully in a number of studies, as they avoid the combinatorial explosion inherent in other methods [27]-[30].

GAs are meta-heuristic algorithms which simulate evolution and natural selection to select solutions in a given generation based on a measure of fitness (the fitness function). The algorithm initialises by randomly creating a population of potential solutions. The fittest solutions in each generation are bred with each other (crossover) to create the next generation. An individual solution's chance of survival is proportional to its fitness. Random mutation is employed in order to diversify the population and reduce the likelihood of convergence to a non-global optimum [31]. Mutation and crossover are controlled by predefined probabilities. There are a number of different ways of defining how many individuals survive from one generation to the next - elitism was used here to ensure that the fittest individual in a given generation was carried forward to the next.

\section{Water Network modelling and specification}

In this work, the pumping schedules of two water supply systems were optimised - the 'Van Zyl' benchmark network, first proposed in [27], and the high-level supply of the city of Belfast, Northern Ireland. Optimisation was carried out using the 'pyevolve' toolkit in Python, integrated with the EPANET water network modelling software [26]. Potential solutions were generated by a GA, which were then evaluated for violation of hydraulic constraints in EPANET before being passed back to the GA to evaluate reservoir level and maximum daily flow constraints. Feasible solutions were scored on the basis of the optimisation objective (fitness function), depending on the scenario.

\section{1. 'Van Zyl' benchmark system}

The 'Van Zyl' test system was first used by Van Zyl et al. in [27] and has been frequently used as a benchmark system for testing optimisation algorithms and investigating new operating procedures. It consists of a reservoir supplying two tanks (at different altitudes) via two primary pumps and one boost pump (see Fig. 3, full system specification in [27]). Demand 


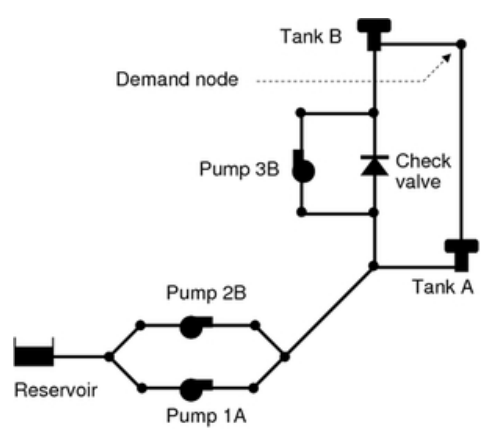

Figure 3: 'Van Zyl' test system

is taken from one node situated between both tanks. There are a large number of potential operating modes for this system, making it an excellent candidate for optimisation and testing of algorithms. Pump power varies slightly depending on the system pressure, but the primary pumps have an operating power of up to $200 \mathrm{~kW}$ while the boost pump consumes up to $50 \mathrm{~kW}$.

\subsection{Belfast System}

The largest component of NIW's supply network is that of the city of Belfast. A model of the Belfast water supply system was developed using data made available by NIW. Belfast is a medium-sized city of approximately 500k inhabitants, who each consume 360 1/day of water on average [17]. Belfast's water supply system is representative of water supply systems on the island of Ireland, where the power system data from this study was taken.

The Belfast water network has a number of interesting characteristics. Most of the city's water supply ${ }_{320}$ comes from two catchments: the Mourne mountains to ${ }_{321}$ the South, and Lough Neagh to the Northwest (Fig. 4). ${ }_{322}$ The pumps at Dunore Point (part of the Lough Neagh ${ }_{323}$ supply) operate against a greater hydraulic head than ${ }_{324}$ those of the Mourne Conduit. Because of this, energy ${ }_{325}$ consumption of the Lough Neagh supply is higher than ${ }_{326}$ the Mourne supply. However, there is a limit of $130{ }_{327}$ $\mathrm{Ml} /$ day on abstraction from the Silent Valley reservoir in ${ }_{328}$ the Mournes, ensuring that both the Mourne and Lough ${ }_{329}$ Neagh supplies are always available to provide Belfast's ${ }_{330}$ water. Details of both sources can be seen in Table 1 .

Data for the Belfast system were obtained from ${ }_{331}$ NIW's Asset Management division, as well as from Ordnance Survey maps and NIW press releases [18][19],[32]. Due to the difficulty with accessing specific data on system operation, a number of approximations 334 were necessary. Service reservoir capacities were 335

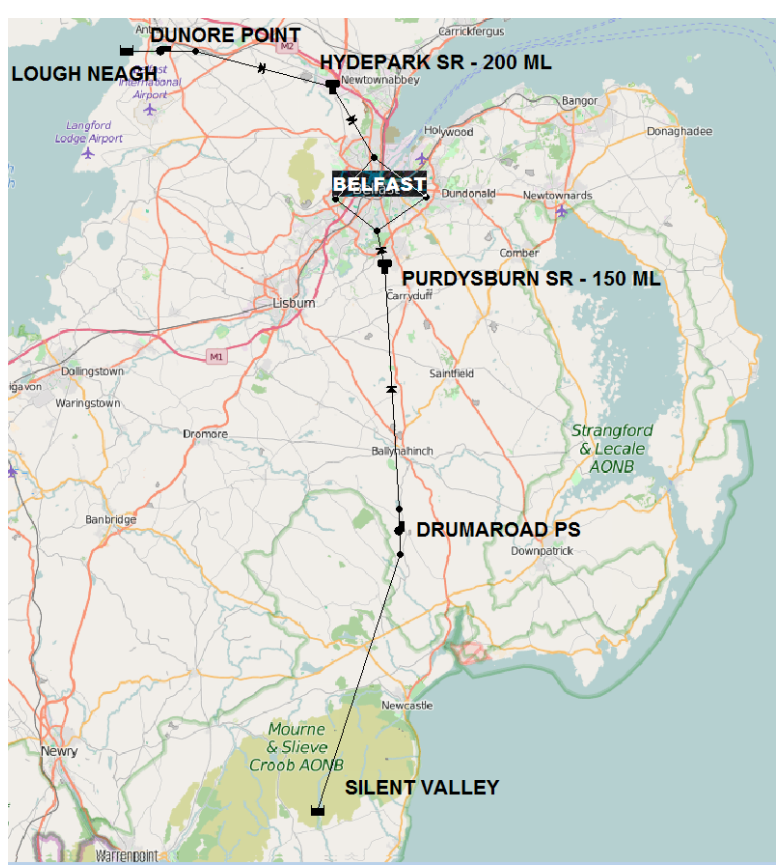

Figure 4: Simplified representation of Belfast water supply (EPANET)

Table 1: Belfast's main sources of water [18] [19]

\begin{tabular}{c|c|c} 
& Mourne Conduit & Lough Neagh \\
\hline Pipe length & $56 \mathrm{~km}$ & $18 \mathrm{~km}$ \\
\hline $\begin{array}{c}\text { Service reservoir } \\
\text { capacity (approx. }\end{array}$ & $150 \mathrm{Ml}$ & $200 \mathrm{Ml}$ \\
\hline Total head gain & $-76 \mathrm{~m}$ & $90 \mathrm{~m}$ \\
\hline Max pumped flow & $130 \mathrm{Ml} /$ day & $180 \mathrm{Ml} /$ day \\
\hline $\begin{array}{c}\text { Pump power } \\
{ }^{*} \text { Approximated from available data }\end{array}$ & $3 \mathrm{MW}$
\end{tabular}

inferred from satellite data, while pump power was calculated from pump flow rates and system head. Pumps were modelled as single-speed units. The water supply of Belfast is not isolated from the rest of the Northern Ireland network, and a small proportion of the water carried is diverted to other areas. In order to reduce the computational complexity of the model this off-take was ignored, and Belfast itself was represented as four equal demand nodes. Static head from the SRs was used to provide system pressure in the city.

\subsection{Scenarios}

For both models, four scenarios were considered:

- Minimise consumption - Minimising energy consumption and calculating cost on the basis of final EP2 price (base case). 


\subsection{Objective Function}

For each scenario, the optimisation objective function was different. In the EA1 and EP2 scenarios, the objective was minimisation of cost (Eq. 1).

$$
\text { minimise: } \quad \sum_{i=1}^{24} E_{i}
$$

In the 'minimise consumption' scenario, it was to minimise the overall quantity of energy consumed (Eq. 2).

$$
\text { minimise: } \quad \sum_{i=1}^{24} P_{p, i} \quad \forall p
$$

The objective of the 'max wind' scenario was to maximise the quantity of wind energy consumed (Eq. 3).

$$
\text { maximise: } \quad \sum_{i=1}^{24} W_{i}
$$

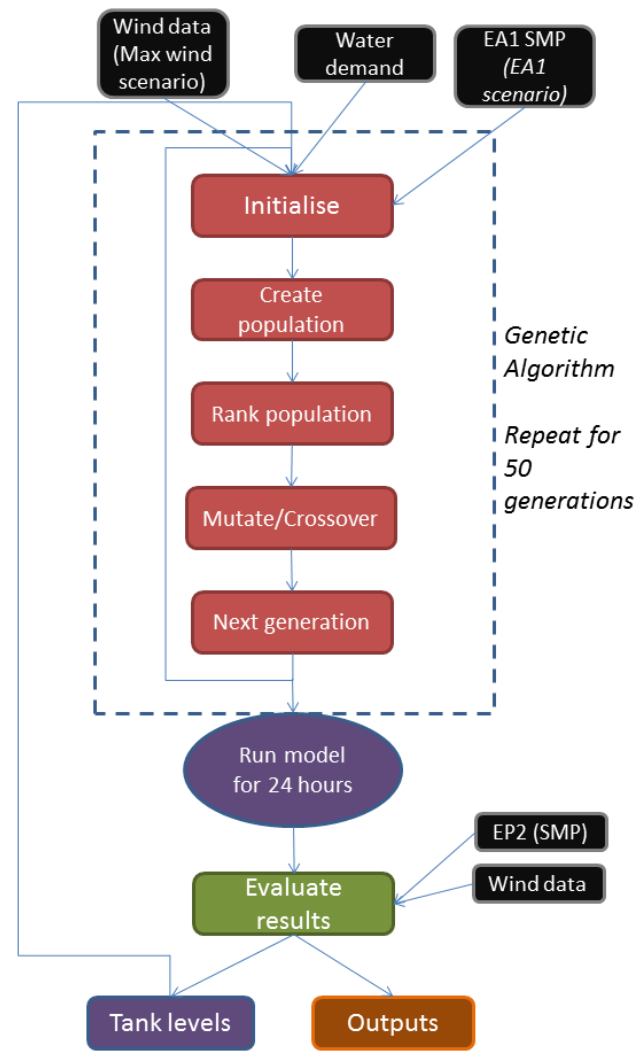

Figure 5: Genetic Algorithm and model methodology

\subsection{Constraints}

For both service reservoirs, the reservoir level at time period $i$ was equal to the reservoir level at time period $i-1$ minus the outflow during $i-1$ plus the inflow during $i-1$.

$$
R_{p, i}=R_{p, i-1}-D_{p, i-1}+F_{p, i-1} \quad \forall p \forall i
$$

The cost of electricity consumption during time period $i$ was equal to the unit cost of electricity during $i$ multiplied by the power consumption of the pumps during the same period.

$$
E_{i}=M_{i} P_{p, i} \quad \forall p \forall i
$$

SR levels were allowed to vary between specified minimum and maximum levels (Eq. 6).

$$
R_{p, \min } \leq R_{p, i} \leq R_{p, \max } \quad \forall p \forall i
$$

\subsection{Belfast Model Constraints}

There were two constraints implemented in the Belfast model that were not in the 'Van Zyl' model - 
abstraction from Silent Valley Reservoir was limited to 403 $130 \mathrm{Ml}$ per day, and a 'mass balance' constraint was en- 404 forced, requiring SR water levels to be at least $90 \%$ of 405 initial level (on 1 April 2012) at the end of each day (see 406 Eq. 7). The 'mass balance' constraint was necessary to prevent reservoirs having insufficient capacity for high- 407 demand days.

$$
\begin{aligned}
& \sum_{i=1}^{24} F_{m} \leq 130 \times 10^{6} \\
& R_{p, i=24} \geq 0.9 R_{p, \text { initial }} \quad \forall p
\end{aligned}
$$

\subsection{Hydraulic Modelling}

The Hazen-Williams equation (Eq. 8), [34] is an empirical formula which models the pressure drop of water 415 flowing in pipes. The EPANET solver uses this equation ${ }_{416}$ to calculate system pressure losses, allowing accurate ${ }_{417}$ calculation of $F$ and $D$ at each time step. Pipes were ${ }_{418}$ modelled as plastic-lined, with a roughness coefficient ${ }_{419}$ (C) of 130 .

$$
\frac{h_{f}}{L}=\frac{10.67 Q^{1.85}}{C^{1.85} d^{4.87}}
$$

\section{Results}

The algorithm output data for each day showing reservoir level variation, pump operation, flow rates, energy consumption and final solution feasibility (a feasible solution was found for all days with both models). Table 2 provides a summary of the salient data.

\section{1. 'Van Zyl' Model}

Despite serving the same demand, the scenarios modelled showed a significant variation in the total 434 amount of water pumped. This is because pump 3B ${ }_{435}$ (see Fig. 3) acted as a top-up pump, transferring water ${ }_{436}$ from one SR to another. The 'max wind' scenario saw 437 this pump used extensively, thus resulting in the higher ${ }_{438}$ energy consumption and pumped flow averages that 439 can be seen in Table 2 .

The 'minimise consumption' scenario consumed ${ }_{442}$ $2 \%$ less electricity then any other scenario while also 443 maintaining the lowest average value of pumped flow. 444 Despite this, it was the most expensive scenario, costing 445 13.4\% more than the EP2-based optimisation (Fig. 6). $\quad 446$

All scenarios showed an increase of wind power ${ }_{447}$ contribution compared to the system average (Fig. 7). 448 Optimising on the basis of the wind penetration saw a 449 large increase of wind contribution - 18.2\% higher than 450 what would be expected from the system average.

EA1 forecast price was consistently lower than the 452 final EP2 price (underestimating final cost by $13.6 \% \quad 453$ on average) but was still cheaper than two of the three other scenarios. This optimisation also showed similar contributions from wind power to the EP2 case.

\subsection{Belfast Model}

All four scenarios of the Belfast model showed very similar values for total pumped flow, as would be expected from the radial nature of this network. Energy consumption and pumped flow do not correlate directly due to the different energy consumptions of both supplies, and the fact that the relationship between flow rate and power depend on the operating head of the system, which vary due to the level in the SRs. The 'max wind' scenario, which paid no heed to the cost or quantity of energy, gave the highest values for pumped flow and power consumption but also saw a $19.7 \%$ increase in wind contribution compared to the system average (Fig. 9) while also being $10.4 \%$ cheaper than the 'minimise consumption' scenario.

A similar pattern of operating cost was evident for the Belfast model as for the 'Van Zyl' model: EP2 optimisation was the cheapest, followed by EA1. The one exception to this was the 'minimise consumption' scenario - this actually produced higher power consumption than either the EA1 or EP2 optimisations. This is due to a cycle observed in the output data, caused by the 24-hour horizon of the optimisation - initially, both service reservoirs would be allowed to drain as much as possible in order to minimise pumping. As the optimisation started again for the following day, both reservoirs would be depleted and significant pumping would be required to maintain water supply. The Lough Neagh supply consumed approximately 2.5 times more energy for each litre of water pumped compared to the Mourne supply. In the price- and wind-based scenarios, more use was made of the cheaper Mourne supply, thus reducing the need for the more expensive Lough Neagh water. In the Belfast model, 'max wind', was cheaper than 'minimise consumption' (Fig. 8). This may have been due to the fact that the 'Van Zyl' 'max wind' scenario consumed significantly more power than the other scenarios (thus increasing energy cost) while the Belfast 'max wind' scenario consumed only slightly more.

EA1 optimisation underestimated the final EP2 cost by $13.8 \%$ on average but saw an increase in wind power contribution of $7.8 \%$

On average, across all scenarios, the Lough Neagh supply provided $51 \%$ more water than the Mourne supply, due to the constraint on abstraction from Silent Valley and the larger volume of the Hydepark SR. 0.16 $\mathrm{kWh}$ were used by the Mourne supply pumps for each 
Table 2: Summary of Results, April 2012 - March 2015

\begin{tabular}{|c|c|c|c|c|}
\hline Daily Averages & Min. Cons. & EA1 & EP2 & Max. Wind \\
\hline \multicolumn{5}{|c|}{ 'VAN ZYL' MODEL } \\
\hline Energy consumption $(\mathrm{kWh})$ & 3628 & 3705 & 3713 & 3885 \\
\hline Final (EP2) cost $(£)$ & 189.6 & 173.8 & 164.2 & 183.1 \\
\hline $\mathrm{EP} 2$ unit cost $(\mathrm{p} / \mathrm{kWh})$ & 4.79 & 4.69 & 4.42 & 4.71 \\
\hline Pumped flow $\left(\mathrm{m}^{3}\right)$ & 14885 & 15359 & 15613 & 16229 \\
\hline Cost per $\mathrm{m}^{3}$ pumped (p) & 1.274 & 1.131 & 1.052 & 1.128 \\
\hline $\begin{array}{l}\text { Expected wind contribution }(\mathrm{kWh}) \\
(18.65 \% \text { system av. penetration) }\end{array}$ & 676.6 & 690.8 & 692.4 & 724.4 \\
\hline Wind contribution (kWh) & $689.8(+1.95 \%)$ & $732.7(+6.06 \%)$ & $745.9(+7.73 \%)$ & $856(+18.17 \%)$ \\
\hline \multicolumn{5}{|c|}{ BELFAST MODEL } \\
\hline Energy consumption $(\mathrm{kWh})$ & 55250 & 55071 & 55045 & 55874 \\
\hline Final (EP2) cost (£) & 2846 & 2425 & 2278 & 2550 \\
\hline EP2 unit cost (p/kWh) & 5.15 & 4.40 & 4.14 & 4.56 \\
\hline Pumped flow $\left(\mathrm{m}^{3}\right)$ & 180449 & 180873 & 180903 & 185957 \\
\hline Cost per $\mathrm{m}^{3}$ pumped $(\mathrm{p})$ & 1.577 & 1.341 & 1.259 & 1.371 \\
\hline $\begin{array}{l}\text { Expected wind contribution (kWh) } \\
\text { (18.65\% system av. penetration) }\end{array}$ & 10303 & 10270 & 10265 & 10419 \\
\hline Wind contribution (kWh) & $10473(+1.65 \%)$ & $11066(+7.75 \%)$ & $11352(+10.60 \%)$ & $12467(+19.65 \%)$ \\
\hline
\end{tabular}

$\mathrm{m}^{3}$ of water supplied, while the Lough Neagh pumps 478 consumed $0.4 \mathrm{kWh}$ for each $\mathrm{m}^{3}$ pumped. This was con- 479 sistent across all scenarios and is due to the fact that the 480 Lough Neagh pumps had to pump against a head of 90481 $\mathrm{m}$, while the Mourne pumps were moving water against ${ }_{482}$ a negative head $(-76 \mathrm{~m})$.

\section{Discussion}

In this research, two water supply systems (the 'Van ${ }^{488}$ Zyl' test system and a model representing the supply 489 for the city of Belfast) were optimised on the basis 490 of minimising electricity consumption, maximising 491 wind power contribution, and minimising electricity 492 cost (using both forecast and actual system price). ${ }^{493}$ Pumping costs and contribution from wind power 494 were quantified, with the Belfast model giving results 495 consistent with the benchmark system.

EP2 optimisation was consistently the least expen- ${ }^{497}$ sive, as might be expected as EP2 represents the final 498 cost of wholesale electricity. It would not be possible to 499 optimise on the basis of EP2 in reality as it is not known 500 until four days after the event, but it represents the most 501 cost-efficient operation possible. EA1 optimisation is 502 achievable, as EA1 data are made available one day 503 in advance. Despite underestimating final costs by 504 approximately 14\%, EA1-based optimisation nonetheless represented a significant saving compared to the non-price-based scenarios. A water utility optimising pumping on the basis of the publicly available SMP forecast could make significant savings compared to normal operation.

It should be noted that all prices discussed here are wholesale prices - they do not reflect the final price a customer would pay as SMP does not include the cost of distribution or transmission. It can be reasonably assumed that this added cost would be fairly constant [35] and would not affect the results seen here, other than to increase the cost of all scenarios by a comparable margin. A further limitation is that neither of the models analysed here included constraints relating to water treatment, which is either a continuous or batch process. Water is treated before being pumped to service reservoirs, with the treatment plant usually being on the same site as the pumping station (as is the case with both Dunore Point and Drumaroad). The Belfast model represents a simplification of the reality, in that the city itself was modelled as four demand nodes and offtake from both conduits for other areas were ignored; however, this should not have a significant effect on the results as the demand was scaled to compensate for the excess water that would have otherwise served areas beyond Belfast, and flow within the Belfast network 


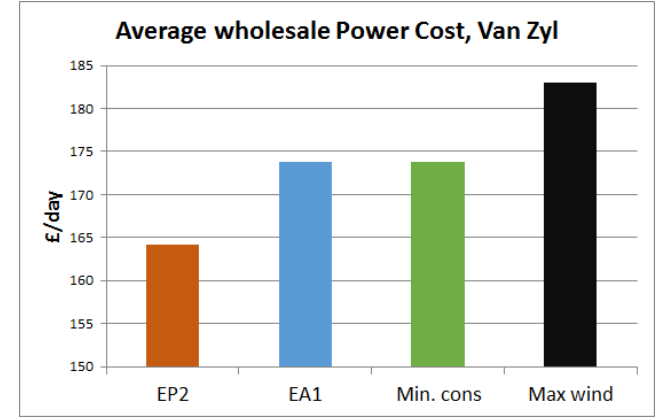

Figure 6: Average SMP energy cost, 'Van Zyl' model

Average daily contribution from wind, Van Zyl (kWh)

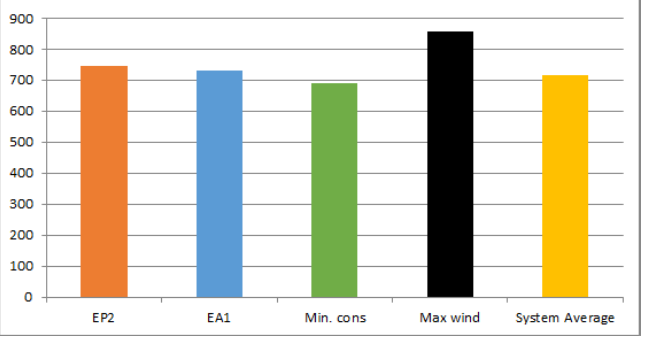

Figure 7: Average contribution of energy consumption from wind, 'Van Zyl' model itself would have little bearing on the demand from the SRs.

For both models, the 'max wind' scenario showed ${ }_{533}$ a significant cost saving compared to the 'minimise ${ }^{534}$ consumption' scenario. Both SMP-based optimisa- 535 tions also showed significant increases in wind power ${ }_{536}$ contribution compared to both the system average and ${ }_{537}$ the 'minimise consumption' scenario. This reinforces 538 the suggestion that there is a correlation between wind ${ }^{539}$ penetration and system price. While not as conducive to high wind contributions as wind-based optimisation, SMP-based optimisation represents a viable means of incentivising demand to react to wind generation. ${ }^{54}$ However, the difference in wind contribution between ${ }_{542}$ the EA1 and EP2 scenarios shows that this link is ${ }_{543}$ dependent on the accuracy of wind forecasting in the ${ }_{544}$ operation of the electricity market. The very high ${ }_{545}$ increases in wind contribution seen in the 'maximise ${ }_{546}$ wind' scenario are also unlikely to be achievable in ${ }_{547}$ reality as they are based on perfect foresight of wind ${ }_{548}$ generation.

In the Irish SEM, the EA1 forecast is updated later 550 on D-1 with an EA2 forecast, and then again on the ${ }_{551}$ morning of the day itself with the WD1 forecast. 552 In practice, an EA1-based pumping schedule could ${ }_{553}$

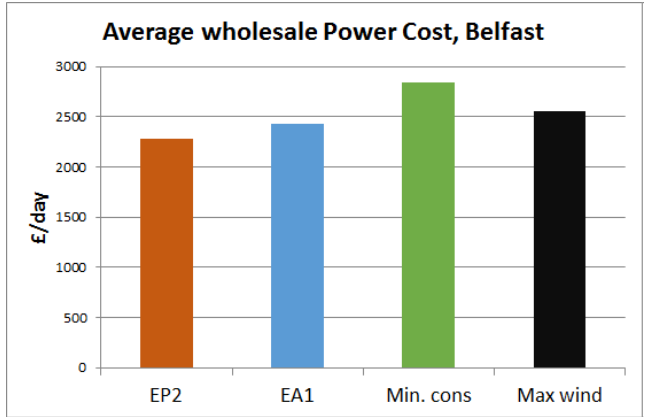

Figure 8: Average SMP energy cost, Belfast model

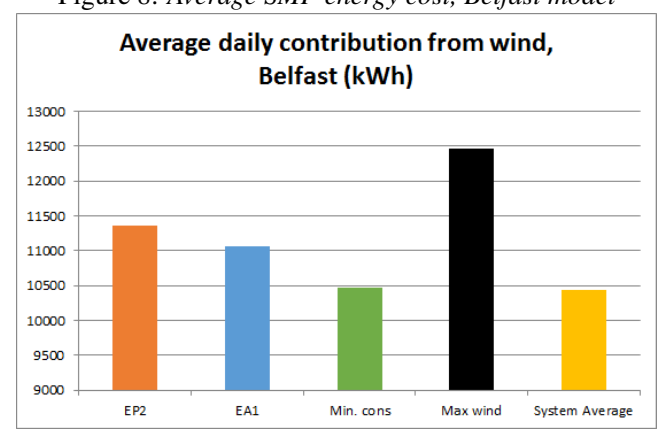

Figure 9: Average contribution of energy consumption from wind, Belfast model

be updated when these forecasts are released. The increased accuracy of these forecasts should correlate with costs and wind contributions closer to those seen in the EP2 scenario. High-wind events are frequently multi-day, and so if a period of sustained high wind was forecast, relaxing the mass balance constraint of the Belfast system could allow tanks to be filled during this period of low cost generation, or allow the water level to gradually deplete in anticipation of such an event.

\section{Conclusion}

The main contribution of this study is in showing that price-based optimisation of water supply provides an opportunity to benefit both the water utility (through reduced cost) and the power system (through increased uptake of wind power). Providing that the consumer is paying a tariff based on the wholesale cost of energy, optimising pump operation on the basis of an SMP forecast would allow the water utility to make significant cost savings compared to normal operation while increasing utilisation of wind generation. In a market such as the Irish SEM, where wind power is pricetaking rather than price-making, optimising on the basis of SMP effectively amounts to market-driven DSM 
(rather than that which involves explicit operator con- 602 trol) which has the advantage of encouraging alignment 603 of energy consumption with wind generation. Optimis- ${ }^{604}$ ing on the basis of the wind penetration itself increases ${ }_{606}^{605}$ the contribution of wind generation even further, while 607 still reducing the cost of electricity. Implementing this 608 in reality would be a more explicit form of DSM, either ${ }^{609}$ by direct signal from the energy utility or by design- 611 ing a tariff based entirely on wind generation rather than 612 SMP.

Both approaches provide advantages for both con- ${ }^{614}$ sumer and system, but a trade-off is required between ${ }_{616}$ cost and wind power uptake. If the system operator 617 wished to maximise wind generation to the fullest ex- ${ }^{618}$ tent, more explicit DSM would be desirable, thus pro- ${ }^{619}$ viding the benefit seen in the 'max. wind' scenario here. ${ }_{621}$ However, if flattening of the load curve was also a prior- 622 ity for the system then SMP-based optimisation would ${ }^{623}$ be advantageous in that it would discourage load during ${ }_{625}^{624}$ peak times (which, due to variable generation, do not al- 626 ways occur at the times reflected by standard multi-rate ${ }^{627}$ tariffs) while also, to a certain extent, promoting utilisa- ${ }^{628}$ tion of wind power.

The methodology used here could be applied to any 631 water supply system, with modifications to suit the 632 needs of the particular system - for example, to take account of water treatment constraints, or daily or sea- ${ }_{635}$ sonal limits on water abstraction. The effectiveness of 636 the method would in large part be dictated by the flow ${ }^{637}$ rate of the pumps and storage capacity of service reser- ${ }_{639}^{638}$ voirs in relation to the water demand. It should also be ${ }_{640}$ noted that the approach detailed here could be applied ${ }^{641}$ to any dispatchable load. If implemented on a sufficient ${ }^{642}$ scale, it would reduce both the need for thermal genera- ${ }^{643}$ tion and for wind power curtailment.

\section{Acknowledgement}

The authors would like to thank Northern Ireland Water for the provision of data and access to system in- 652 formation, and the NI Department of Employment and ${ }^{653}$ Learning for project funding.

\section{References}

[1] European Environment Agency, "Europe's onshore 660 and offshore wind energy potential", Tech. Rep. no. 6/2009, [online]. Available: https://www.energy. 662 eu/publications/a07.pdf

[2] McGarrigle, E.V., Deane, J.P., Leahy, P.G., "How much ${ }^{664}$ wind power will be curtailed on the 2020 Irish power 665 system?", Renew. Energ., vol 55, pp. 544-553, 2013.
[3] Sustainable Energy Authority of Ireland, "Ireland's energy targets: progress, ambition and impacts - summary for policy makers", Tech. Rep., April 2016, [online]. Available: https://www.seai.ie/Publications/ Statistics_Publications/Energy_Modelling_ Group_Publications/Ireland\%E2\%80\% 99s-Energy-Targets-Progress-Ambition-and-Impacts. pdf

[4] Wu, D., Javadi, M., Jiang, J.N., “A preliminary study of impact of reduced system inertia in a low-carbon power system", Jour. of Mod. Power Sys. Clean Energ., vol 3, no. 1, pp. 82-92, 2015.

[5] Eirgrid Group, "DS3 Programme operational capability outlook 2016", Tech. Rep., [online]. Available: http://www.eirgridgroup. com/site-files/library/EirGrid/ DS3-Operational-Capability-Outlook-2016. pdf

[6] Cohen, A.I., Wang, C.C., "An optimization method for load management scheduling," IEEE Trans. Power Sys., vol. 3, no. 2, pp. 612-618, 1988.

[7] Qian, L.P., Zhang, Y.J., Huang, J., Wu, Y., "Demand response management via real-time electricity price control in smart grids", IEEE Jour. Sel. Areas in Comm., vol. 31, no. 7, pp. 1268-1280, 2013.

[8] Adika, C.O., Wang, L., "Autonomous appliance scheduling for household energy management", IEEE Trans. Smart Grid, vol. 5, no. 2, pp. 673-682, 2014.

[9] Pourmousavi, S.A., Patrick, S.N., Nehrir, M.H., "Realtime demand response through aggregate electric water heaters for load shifting and balancing wind generation", IEEE Trans. Smart Grid, vol. 5, no. 2, pp. 769 $777,2014$.

[10] Vanthournout, K., Dupont, B., Foubert, W., Stuckens, C., Claessens, S., "An automated residential demand response pilot experiment, based on day-ahead dynamic pricing", Appl. Energy, vol. 155, pp. 195-203, 2015.

[11] van Staden, A.J., Zhang, J., Xia, X., "A model predictive control strategy for load shifting in a water pumping scheme with maximum demand charges", Appl. Energy, vol. 88, pp. 4785-4794, 2011.

[12] Roos, J.G., Lane, I.E., "Industrial power demand response analysis for one-part real-time pricing", IEEE Trans. Power Sys., vol. 13, no. 1, pp. 159-164, 1998.

[13] Logenthiran, T., Srinivasan, D., Shun, T.Z., "Demand side management in smart grid using heuristic optimization", IEEE Trans. Smart Grid, vol. 3, no. 3, pp. 1244-1252, 2012.

[14] Finn, P., O'Connell, M., Fitzpatrick, C., "Demand side management of a domestic dishwasher: Wind energy gains, financial savings and peak-time load reduction", Appl. Energy, vol. 101, pp. 678-685, 2013.

[15] Finn, P., Fitzpatrick, C., "Demand side management of industrial electricity consumption: Promoting the use of renewable energy through real-time pricing", Appl. Energy, vol. 113, pp. 11-21, 2014.

[16] Gholian, A., Mohsenian-Rad, H., Hua, Y., "Optimal industrial load control in smart grid", IEEE Trans. Smart Grid, vol.7, no.6, pp. 2305-2316, 2016.

[17] NI Water, "Annual Report 2014-15", [online]. Available: https://www.niwater.com/sitefiles/ resources/pdf/reports/annualreport/ niwannualreport2014-15.pdf

[18] UK Water Projects 2009,"Project Alpha”, [online]. Available: http://www.waterprojectsonline. 
com/case_studies/2009/NIW_Alpha_2009.pdf

[19] NI Water, "Silent Valley information leaflet", [online]. Available: https://www. niwater.com/sitefiles/resources/pdf/ silent-valley-information-leaflet.pdf

[20] CER, "CER factsheet on the Single Electricity Market", 2011, [online]. Available: http://www.cer. ie/docs/000262/cer11075.pdf

[21] SEM-O, "Pricing and scheduling frequently asked questions", [online]. Available: http: //www.sem-o.com/Publications/General/ Pricing\%20and\%20Scheduling\%20FAQ.pdf

[22] Paudyal, S., Cañizares, C.A., Bhattacharya, K., "Optimal operation of industrial energy hubs in smart grids", IEEE Trans. Smart Grid, vol. 6, no. 2, pp. 684-694, 2015.

[23] Jowitt, P.W., Germanopoulos, G. "Optimal pump scheduling in water-supply networks", Jour. Water Res. Plan. Mgmt., vol. 118, no. 4, pp. 406-422, 1993.

[24] Chase, D.V., Ormsbee, L.E., "Computer-generated pumping schedules for satisfying operating objectives", Jour. Amer. Water Works Ass., vol. 85, no. 7, pp. 54-61, 1993.

[25] Zhuan, X., Xia, X, "Optimal operation scheduling of a pumping station with multiple pumps", Appl. Energy, vol. 103, pp. 250-257, 2013.

[26] US Environmental Protection Agency, "EPANET", [online]. Available: https://www.epa.gov/ water-research/epanet

[27] Van Zyl, J.E., Savic, D.A., Walters, G.A., "Operational optimization of water distribution systems using a hybrid genetic algorithm", Jour. Water Res. Plan. Mgmt., vol. 130, no. 2, 2004.

[28] López-Ibáñez, M., Devi Prasad, T., Paechter, B., “Optimal pump scheduling: representation and multiple objectives", CEC, Napier University, Edinburgh, Scotland, Tech. Rep., 2012.

[29] Moreira, D.F., Ramos, H.M., "Energy cost optimization in a water supply system case study", Hindawi Jour. Energy, vol. 2013.

[30] Ramos, H.M., Costa, L.H.M., Gonçalves, F.V., "Energy efficiency in water supply systems: GA for pump schedule optimization and ANN for hybrid energy prediction”, Intech Water Supply System Analysis - Selected Topics, Chapter 4, 2012.

[31] Goldberg, D.E., Genetic Algorithms in search, optimization and machine learning, Boston, USA: Addison-Wesley Longman, 1989.

[32] UK Water Projects 2003, "Aquarius 3 Mourne water treatment works", Tech. Rep., [online]. Available: http://www . waterprojectsonline.com/case_ studies/2003/NI_Water_Mourne_2003.pdf

[33] Kernan, R., Liu, X., McLoone, S., Fox, B., "Management of public water supply to reduce power cost and improve wind power uptake", presented at the 16th IEEE EEEIC, Florence, Italy, 2016

[34] American Society of Plumbing Engineers, "Hazen Williams formula",Plumbing Engineering and Design Handbook of Tables, [online]. Available: https://www . aspe.org/sites/default/files/ webfm/pdfs/TableBookErrata.pdf

[35] CER, "Factsheet: Electricity prices in Ireland", Tech. Rep., [online]. Available: http://www.cer.ie/ docs/000671/cer10062.pdf 